\title{
Comments on
}

"Making Policy in a Changing World" by William C. Brainard and George L. Perry

$$
\text { by }
$$

John B. Taylor

Stanford University

\author{
Prepared for the Yale-Brookings Conference, \\ "Economic Events, Ideas, and Policies: The 1960s and After," \\ November 12 and 13, 1999
}

I want to thank Bill Brainard and George Perry for inviting me to this conference on the 1960s and after, in the memory of Arthur Okun. It is a pleasure to participate. I had the opportunity to meet Arthur Okun in the mid 1970s when I was in Washington working on the staff of the Council of Economics Advisers (CEA). I have always admired his ability to translate complex macroeconomic ideas into simple, quantitative, and highly useful constructs, such as potential GNP and Okun's law.

As a macroeconomist, the 1960s have always been an interesting period for me. I first got interested in macroeconomics when I was a college student in the 1960s. One reason that I was attracted to macroeconomics was a fascination with how new quantitative methods were being used to help formulate policy in Washington. My undergraduate thesis project was on monetary and fiscal policy rules, which I viewed as part of the same quantitative approach that Arthur Okun and others were using at the CEA. I was interested in dynamic stability issues, following the methodology of A.W. Phillips, Will Baumol, and Phil Howrey (the latter two were at Princeton where I was in college at that time). I think the approach taken to quantitative formulation of policy at the CEA in the 1960s still has a significant influence on normative policy evaluation. For 
example, potential GDP (though now meant to mean a level of real GDP around which actual real GDP fluctuates, rather than an upper bound) and the deviations from potential GDP figure prominently in current monetary policy research (see Orphanides, Porter, Reifschneider, Tetlow, and Finan (1999), for example). Potential GDP is a factor in the simple monetary policy rule I suggested in the early 1990s (Taylor (1993)).

I enjoyed reading the paper by Bill Brainard and George Perry. It is a highly original endeavor, characterizing the uncertainty faced by policymakers from the 1960s through the present. I found the "backward" filter calculations of productivity growth, and the wage-price equations to be fascinating, and potentially important for interpreting history. One important application, which I think should be pursued further, is the problem of estimating changes in potential GDP growth. For example, some argue that policy makers were too slow to react to the slowdown in productivity growth in the 1970 s (see Orphanides (1998)). This may have been one reason why the Fed was too easy in certain periods in the 1970s. Orphanides (1998) uses contemporary estimates of potential GDP from the CEA as evidence. An alternative estimate would be based on the backward filters of productivity in Figure 1 of the Brainard-Perry paper. The backward filter estimates in Figure 1 of the paper show that the slowdown was occurring as soon as the late 1960s. To get another measure of how things may have looked, one could start the backward filter in 1975 or 1976 rather than in 1995, as Brainard and Perry have done. Even if one questioned such a calculation as a descriptive device of how policymakers viewed the world back then, it might give an indication of how such methods would work today, say for estimating the size of the potential GDP growth pick-up. 
Rather than focus my comments solely on the econometric methodology, I will spend most of my time on their interpretations of the results. In doing so I will be meeting the discussant's responsibility of concentrating on the parts of the paper I disagree with. My comments can be divided into three parts: First, I want to comment on their interpretation of the results as implying that there is no NAIRU or equivalently that there is a long run Phillips curve trade off. Second, I want to comment on their historical review of economic performance, in which they argue that the 1960s were good, the 1970s and 1980s were bad, and the 1990s were good again. Third, I want to comment on their conclusion that their results add weight to the discretion side of the "rules versus discretion" debate.

\section{Bringing Endogenous Expectations Back Into the Analysis}

Brainard and Perry conclude that there is no NAIRU in their model: "our estimates do not suggest a Nairu anywhere during the four decade period over which we estimate," implying that there is a long run trade off between the inflation rate and the unemployment rate: higher inflation would imply lower unemployment. This view is implicit in their calculation of specific unemployment rates corresponding to a 2 percent inflation rate in the paper. I know that they are guarded in drawing policy implications from this interpretation, but I worry that their interpretation gives a misleading view of the macroeconomic history and could therefore be misleading in the future.

Let me start by stating how a simple look at the facts of U.S. inflation and unemployment over the last 50 years shows a near zero correlation between inflation and unemployment over the long run, thereby indicating that there is no long run tradeoff 
between inflation and unemployment. It is best to take averages over long periods of time--decades, so that we have a measure of the long run. In the 1950s and early 1960s we had low inflation; in the late 1960s and 1970s we had high inflation; and again in the late 1980s and 1990s we had low inflation. But the average unemployment rate in all these periods is roughly the same, around 5 or 6 percent. If anything, unemployment was higher during the high inflation periods than in the low inflation periods, indicating a slight positive correlation between inflation and unemployment. In any case, one cannot see any long run negative trade-off in the post World War II inflation and unemployment data using these simple averages.

However, this is not what the estimated equations of Brainard and Perry show. The sum of the coefficients on lagged inflation in their wage and price equations never gets as high as one. Thus, their estimates can be interpreted as stating that there is a permanent long run tradeoff between inflation and unemployment: Higher inflation will result in lower unemployment.

However, they do find that their estimated long run tradeoff shifts by a large amount. These shifts are illustrated in Figure 1 of these comments. Brainard and Perry find that the unemployment rate associated with 2 percent inflation is around 2 percent in the 1960s, around 9 percent in the late 1970s and early 1980s, and around 3 percent in the 1990s (these estimates use the "prime age" male unemployment measures and are drawn from the "Contemporary filters" section of their Table 1). I show these three unemployment rate estimates in Figure 1 where I have sketched three long-run Phillips curves. The three levels of unemployment-corresponding to the 1960s (shown as 1965), the late 1970s and early 1980s (shown as 1980) and the 1990s (shown as 1995)— 
are found at the intersection of three long run Phillips curve tradeoffs. Thus, the long run Phillips curves that I have sketched in Figure 1 correspond to the long run tradeoffs implicit in the Brainard-Perry wage equations for those three years.

These shifts show how Brainard and Perry's equations (which have a long run trade off) fit the data (which show no long run trade-off). From the 1965 to 1980 the curve shifts to the right; then, from 1980 to 1995 , the curve shifts back to the left. By shifting the curves, the period of high inflation and roughly average unemployment in the late 1970s and early 1980s (before the disinflation) can be placed on the upper part of the “1980” curve.

The problem I have with their interpretation is that these shifts are portrayed as exogenous to policy, while in fact I think they are very much endogenous to policy. Note that the sum of the coefficients on lagged inflation in the wage inflation equations rises and falls as historical inflation rates rise and fall—again see Table 1 of their paper. This is one reason why the unemployment rate associated with 2 percent inflation moves higher and then lower. Thus, one can interpret the rightward and leftward shifts of the curves in Figure 1 as shifts up and down due mainly to changes in expectations of inflation. In my view, the reason the curves shifted from the 1960 s to the 1970 s was that policy led to higher inflation, which shifted up inflationary expectations.

This higher inflation and higher expectations of inflation required a difficult period of disinflation in the early 1980s. Policy makers should be concerned about having to go through such a painful process in the future, and they therefore should guard against it. Expectations of inflation and the Phillips curve may indeed appear to be exogenous to policy; however, as one tries to use policy to move systematically along the 
curve, then expectations of inflation will rise, and the curve will begin to shift up. This rise of inflation will eventually require a painful policy to bring it back down. To help avoid such an event I think it is important to incorporate endogenous expectations (perhaps even rational expectations as an approximation) into the analysis. At the least, one needs to emphasize that the changing parameters (the coefficients on the lagged inflation rates) are endogenous to policy.

\section{Defining Episodes of Macroeconomic Stability and Policy Regimes.}

Bill Brainard and George Perry characterize the economic performance of the last 40 years as follows. "The era that is the subject of this conference begins and ends with decades of outstanding U.S. performance. In both the 1960s and the 1990s, the economy surpassed what seemed achievable in light of what had come before.... [The] long expansion of the 1990s was preceded by two decades in which inflation was a stubborn problem and estimates of attainable unemployment rates had drifted pessimistically higher." In other words, they say that the 1960s and 1990s were good, and the 1970s and 1980s were bad.

I disagree with this interpretation of history; moreover the different episodes do not correspond to any quantitatively documented differences in policy, so it is difficult to relate economic performance to changes in policy. In my view there is an alternative definition of episodes in which changes in economic performance can be related to specific documented changes in economic policy.

The alternative characterization of episodes does not start or end with any particular decade, and it overlaps different policy makers. It defines a watershed in the 
early 1980 s, around the time of the end of the disinflation. In my view macroeconomic stability—as measured by the fluctuations of real output and prices, by the length of expansions, by the frequency of recessions, or by the softness of slowdownsmuch better since this watershed of the early 1980s than during any period of similar length before it.

Consider the volatility of real output—either deviations of real GDP from potential GDP, or the size of the fluctuations in the growth rate of real GDP. Figure 2 shows the GDP gap since 1959 using a Hodrick-Prescott trend as measure of potential GDP. This trend captures the productivity slowdown of the early 1970s; better estimates of potential GDP that formally take productivity and labor force growth into account would provide a similar picture. The volatility of real output seems much smaller than in earlier periods, even the shorter period of the 1960s. The two horizontal lines at the maximum and minimum deviations since the early 1980s are meant to help visualize the reduced volatility. Figure 3 shows the same reduced volatility using the quarterly growth rates of real GDP rather than the GDP gap.

The following table summarizes the visual evidence in the pictures showing the standard deviation of the GDP gap $\left(\sigma_{\text {gap }}\right)$ or the real GDP growth rate $\left(\sigma_{\text {growth }}\right)$ using the data in Figures 1 and 2:

\begin{tabular}{|l|l|l|}
\hline Period & $\sigma_{\text {gap }}$ & $\sigma_{\text {growth }}$ \\
\hline $1959.2-1999.3$ & 1.6 & 3.6 \\
\hline $1959.2-1982.4$ & 1.8 & 4.3 \\
\hline $1982.4-1999.3$ & 1.1 & 2.3 \\
\hline $1960.1-1969.4$ & 1.3 & 3.5 \\
\hline
\end{tabular}


The period since the early 1980s (the fourth quarter of 1982 to be exact) has the greatest macroeconomic stability of the periods shown, confirming the visual evidence in Figure 1 and 2.

One can also make a comparison based on the length of expansions or the frequency of recessions. The period of the 1980s and 1990s contains the first and second longest peacetime expansions in U.S. history, back-to-back and separated by a relatively short recession. If one does not restrict oneself to peacetime, it contains two of the three longest expansions in U.S. history, again back-to-back. Such a long period of stability is unprecedented. The longest expansion occurred in the 1960s, but that long expansion was preceded and followed by short expansions,

There is another reason to choose the early 1980s as the watershed. There was a big shift in U.S. monetary policy toward price stability at that time. I am not referring solely to the disinflation - though that was a necessary part of the transition toward a policy of price stability. I am referring to the difference in the way policy has been conducted since the disinflation compared with before the disinflation. You can see this difference in terms of a policy rule that describes Fed action. The response of the Fed to inflation has been larger in the more recent period; the response of the federal funds rate to an increase in inflation has doubled, and the reaction of the federal funds rate to real output is also larger. (See Taylor (1999) for a review of the estimated responses.)

It is not surprising that we got an increase in price stability as a result of a policy that has focused more on price stability. What may appear more surprising is that we got an increase in output stability too. I think the reason is that a monetary policy that has focused more on price stability has prevented the large run ups of inflation that have 
preceded previous recessions; in other words, the problem of the boom-bust cycle had diminished. There are, of course, other candidate explanations for the improved output stability during the two long expansions of the 1980s and 1990s, including smaller shocks, but in my view the change in monetary policy is the major factor (see Taylor (1998) for a review of other factors and an explanation of the role of monetary policy.)

\section{Implications of Uncertainty for Rules versus Discretion}

Finally I would like to focus on the rules versus discretion issue raised in the paper. Bill Brainard and George Perry state "our conclusion that policy should be framed with continuing attention to changing parameters strengthens the arguments for discretionary policymaking." To be sure, there are many semantic issues in the rules versus discretion debate, and, in practice, monetary policy rules are used as guidelines from which policy makers must deviate in special cases such as a liquidity crisis (see Taylor (1993) for further discussion). Nevertheless, as a general statement I do not agree at all with this conclusion that the uncertainty results tilt the debate toward discretion.

First, parameter uncertainty makes life difficult for policy makers whether they are trying to use rules to guide policy or not. For example, not knowing potential GDP growth, or the natural rate of unemployment, will make it difficult to decide whether you should raise or lower interest rates, whether or not you are using a policy rule as a guideline.

Second, in my view, it is easier to take account of the uncertainty, which Brainard and Perry document quantitatively, through a policy rule approach than through a discretion-oriented approach. Stochastic optimization methods that underlie policy rules 
research take account of the uncertainty explicitly. How do you take account of such research findings about uncertainty otherwise? For example, how do you take account of a finding that the coefficient on the unemployment rate follows a random walk with a standard deviation of 1.4 if you are using discretion? In fact, seminal research by Bill Brainard on optimal control with parameter uncertainty showed the benefits of formal policy approach a long time ago. And George Perry's research on demographic adjustments to the unemployment rate has provided a procedure that can be used with policy rules that react to the gap between the unemployment rate and the natural rate, or other measures of capacity utilization. The newer work in this paper can also be helpful in improving policy rules: most likely one will find that policy should down weight the coefficients in policy rules because of the parameter uncertainty a la Brainard, but in complex dynamic models the adjustment could be up rather than down.

There are many reasons why a monetary policy that is built on a rules-based, systematic, transparent framework works well. Brainard and Perry have provided the kind of research in this paper that can make such an approach work even better in the future. In sum, my view is that the Brainard-Perry research on quantifying uncertainty enables policy to be more rule-like, and in this sense strengthens the arguments for rules rather than for discretion. 


\section{References}

Orphanides, Athanasios (1998), "Monetary Policy Rules Based on Real-Time Data," Finance and Economics Discussion Series, Working Paper 1998-03, Board of Governors of the Federal Reserve System.

Orphanides, Athanasios, Richard Porter, David Reifschnieder, Robert Tetlow, and Fredrico Finan (1999), "Errors in the Measurement of the Output Gap and the Design of Monetary Policy," Finance and Economics Discussion Series, Working Paper 1999-45, Board of Governors of the Federal Reserve System.

Taylor, John B. (1993), "Discretion versus Policy Rules in Practice," Carnegie Rochester Conference Series on Public Policy, North Holland, 39, 195-214.

Taylor, John B. (1998) "Monetary Policy and the Long Boom," Review, Federal Reserve Bank of St. Louis, December.

Taylor, John B. (1999) “A Historical Analysis of Monetary Policy Rules,” in John B. Taylor (Ed), Monetary Policy Rules, University of Chicago Press. 


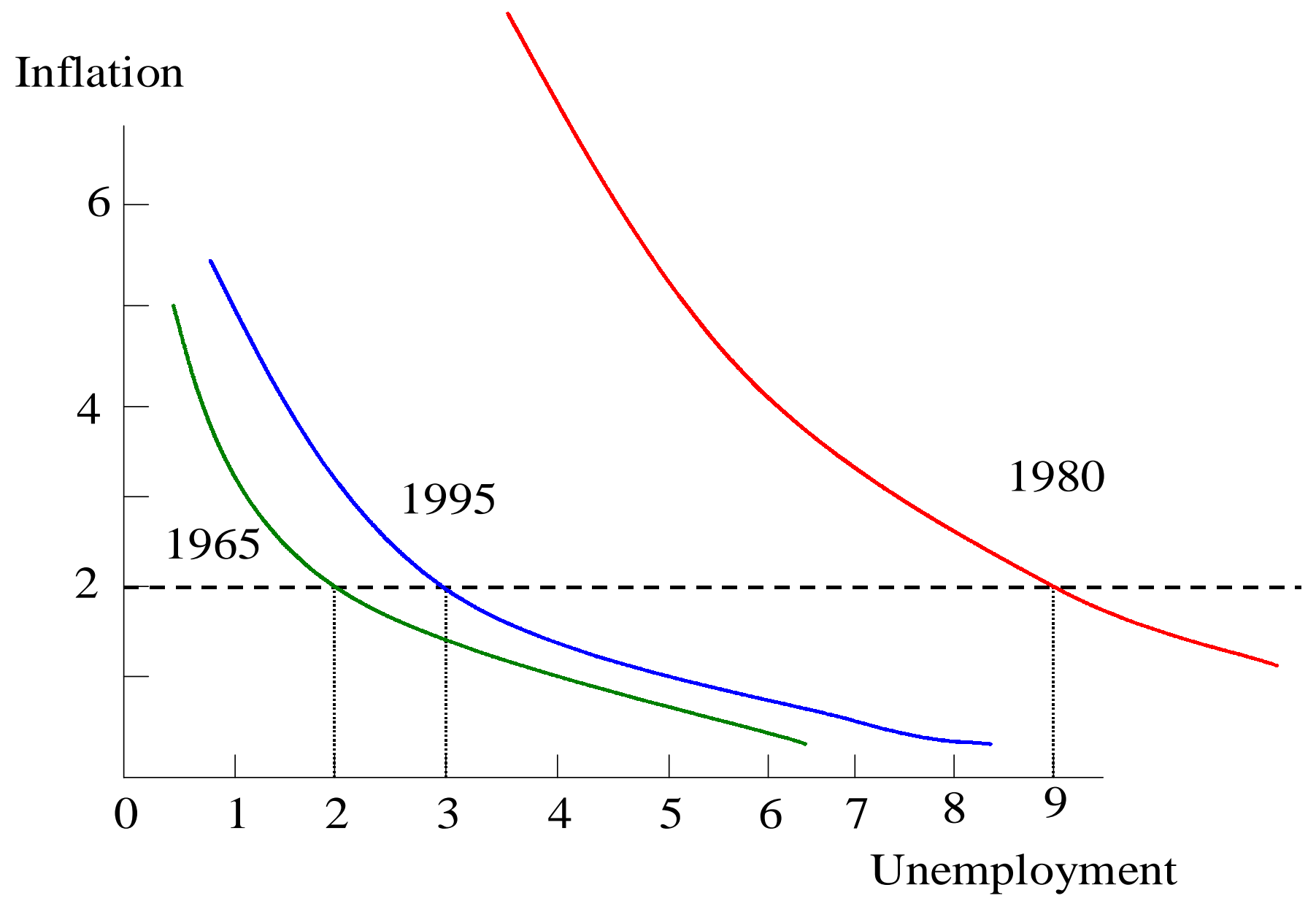

Figure 1. Three Long-Run Phillips Curves Corresponding to Three Unemployment Rates Associated with 2 Percent Inflation. The unemployment rates are rounded versions of those reported in the middle panel of Table 1 of the Brainard-Perry paper and the curves are sketched to pass through those points. 


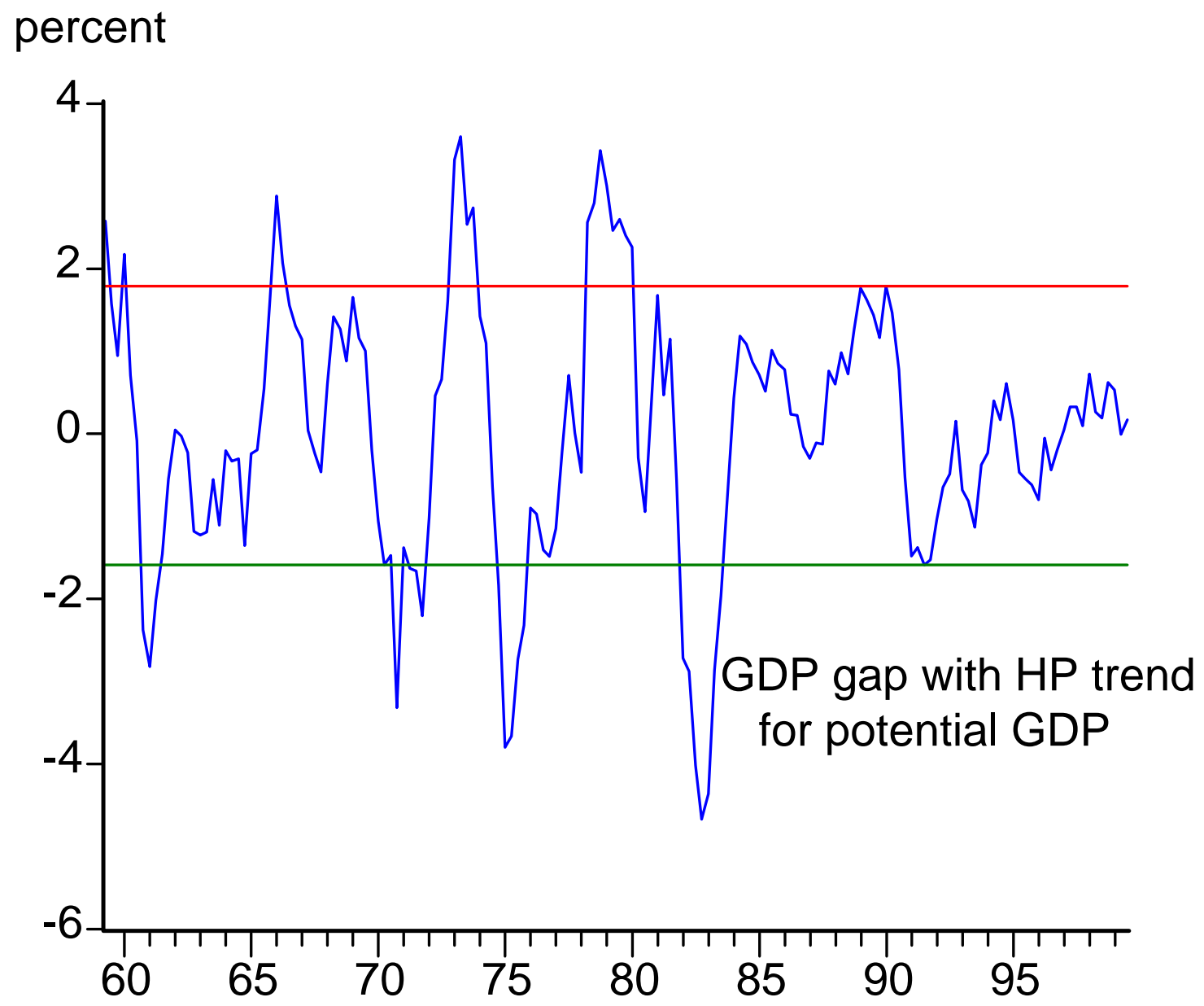

Figure 2. Percentage deviations of real GDP from trend. The plotted series is ( $\log ($ real GDP) - HPTrend $* 100$, where HPTrend is the Hodrick-Prescott filter of log (real GDP). Real GDP was downloaded from BEA on November 3, 1999. 


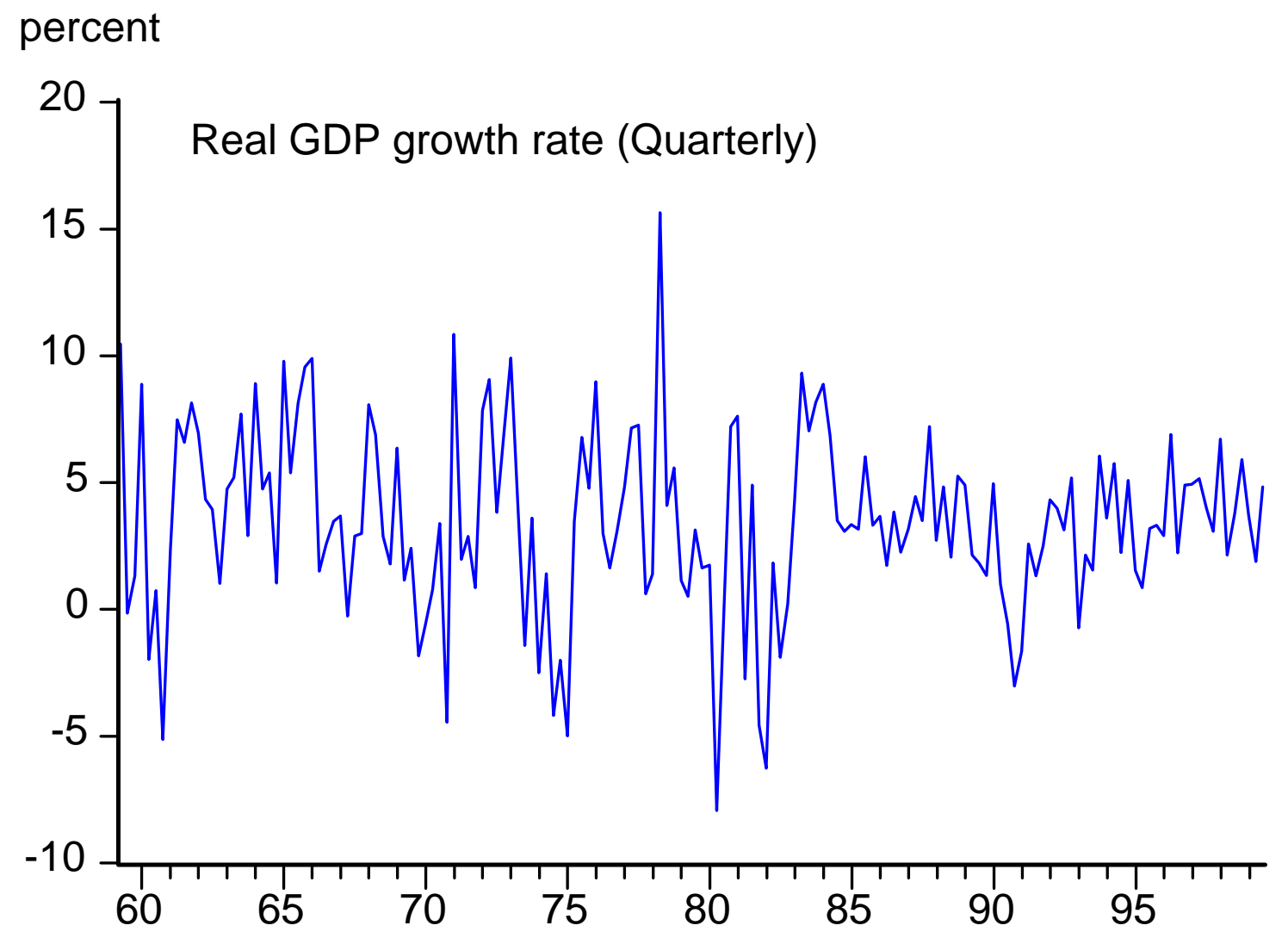

Figure 3. Quarterly Growth Rate of Real GDP.

Source: Downloaded from BEA on November 3, 1999 